Running Head: Respect at Work

\title{
When Does Respectful Engagement with One's Supervisor Foster Help-Seeking Behaviors and Performance?
}

\author{
Anat Friedman \\ Interdisciplinary Studies Unit \\ Bar-Ilan University \\ Ramat Gan 52900, Israel \\ Phone: +972-52-364-6045 \\ anatfr.af@gmail.com \\ Abraham Carmeli* \\ Coller School of Management \\ Tel Aviv University \\ Ramat-Aviv, Tel Aviv 69978, Israel \\ Phone: +972-3-640-6335 \\ Fax +972-3-640-9983 \\ Email: avic@post.tau.ac.il \\ Jane E. Dutton \\ Stephen M. Ross School of Business \\ University of Michigan \\ 701 Tappan Street, Room R4356 \\ Ann Arbor, MI 48109-1234 \\ Phone: 734.764 .1376 \\ Fax: 734.936 .6631 \\ Email: janedut@umich.edu
}

${ }^{*}$ Corresponding author.

Keywords: Respect, psychological safety, discretionary behaviors, job performance, help-seeking behaviors.

Acknowledgements: We appreciate the editor and our anonymous reviewers for their constructive and helpful feedbacks which helped us improving our work. We also would like to thank Ayala Cohen and Etti Doveh for their help with the data analysis, as well as James Jensen and Esther Singer for their editorial comments. We acknowledge the financial support of the Henry Crown Institute of Business Research in Israel at the Faculty of Management, Tel Aviv University. An earlier version of the paper was presented at the 2015 AOM meeting in Vancouver, Canada.

Friedman, A., Carmeli, A., \& Dutton, J.E. When Does Respectful Engagement with One's Supervisor Foster Help-Seeking Behaviors and Performance? Journal of Vocational Behavior, Forthcoming. 
Anat Friedman

Anat Friedman has completed her Ph.D. at Bar-Ilan University. Her research interests focus on conflict management, negotiation, and interpersonal relationships in organizations.

Abraham Carmeli

Abraham Carmeli is a faculty member at Coller School of Management at Tel Aviv University and Surrey Business School at the University of Surrey. He received his Ph.D. from the University of Haifa. His current research interests include leadership and top management teams, relational dynamics, learning from failures, and creativity and innovation in the workplace.

Jane E. Dutton

Jane Dutton is the Robert L. Kahn Distinguished University Professor Emerita of Business Administration and Psychology at the University of Michigan. She received her Ph.D. from Northwestern University. Her current research interests focus on compassion and organizations, positive identity process and relational dynamics at work. 
Running Head: Respectful Engagement, Help Seeking, and Performance

\begin{abstract}
We developed an integrative logic for why respectful engagement with supervisors would encourage and enable help-seeking from coworkers, resulting in greater levels of task performance. Using time-lagged data, the results of a moderated-mediated model supported our theorizing that respectful engagement between employees and their supervisors is key to fostering help-seeking behaviors. Our results suggest respectful engagement fosters help-seeking behaviors particularly when employees report lower levels of psychological safety. Those helpseeking behaviors consequentially improve employee performance. We use these results to suggest how and when workplace relationships endogenously resource individuals to engage and achieve higher levels of job performance.
\end{abstract}

Keywords: Respect, psychological safety, discretionary behaviors, job performance, help-seeking behaviors, group value model, relational model of authority. 


\section{When Does Respectful Engagement with One's Supervisor Foster Help-Seeking Behaviors and Performance?}

The workplace provides numerous opportunities for coworkers to give and to receive help. Helping is a pro-social behavior that is pervasive in organizations where tasks are increasingly interdependent and complex (Podsakoff, MacKenzie, Paine, \& Bachrach, 2000). Collaboration in such situations is not only needed (Grant \& Patil, 2012; Taber \& Deosthali, 2014), but is essential for carrying out work duties (Perlow, 1999; see Grodal, Nelson, \& Siino, 2015). Helping involves both help-seekers and help-givers. Our focus here is on help-seeking, as this is an important behavior in work organizations (Gino \& Schweitzer, 2008) that occurs daily when a person makes requests for resources from others at work (Mueller \& Kamdar, 2011).

Seeking and providing professional help may be instrumental for a member's capacity to address demands and take on task-related issues. Research reveals several mechanisms by which one's job performance can improve. One mechanism for improving job performance is through the seeking of professional (work-related) help in organizations. Improvements in job performance arises from greater motivation and capacity for learning, the acquisition and development of new skills such as problem solving, the boosting of competence which enhance performance (Anderson \& Williams, 1996; Bamberger, 2009; Brooks, Gino, \& Schweitzer, 2015; Dovidio, Piliavin, Schroeder, \& Penner, 2006; Lee, 1997). Further, recent research suggests that greater attention should be directed to the study of the context in which individuals are motivated to ask for professional help (Mueller \& Kamdar, 2011), and to the study of the performance implications of help-seeking as enacted in the workplace (Geller \& Bamberger, 2012). Scholars alert us that the link between help-seeking and performance is largely contingent and that this discretionary behavior depends on the workplace context, such that positive 
outcomes may not be realized (Geller \& Bamberger, 2012, p. 493). For example, when one seeks help from another person and the latter (helper) does not provide the kind of help the help-seeker is hoping for this cannot only result in feelings of discomfort but also affect the performance of the help-seeker (Newark, Bohns, \& Flynn, 2017). Others have pointed to the importance of behavioral configurations of helpers and recipients in shaping the interpersonal dynamics such that they will be more or less beneficial for performance improvements (Golan \& Bamberger, 2015). Thus, key theoretical puzzles focus on the context in which help-seeking is enacted and when it increases performance.

When considering the context in which help-seeking is enacted, scholars also note that our understanding of the underlying sources which fuel the seeking of professional help needs further development (Bamberger, 2009). Particularly, a focus on the help-seeker and his/her perspective can deepen understanding of how interactions unfold (Grodal, Nelson, \& Siino, 2015). Thus, an emphasis on interpersonal conditions is a promising avenue to investigate one's help-seeking behavior (Newman, 2006). However, this focus on interpersonal conditions has remained relatively underdeveloped (Hofmann, Lei, \& Grant, 2009; Lee, 1997, 2002; see van der Rijt Van den, Bossche, van de Wiel, De Maeyer, Gijselaers, \& Segers, 2013, p. 260). The promise of greater attention to interpersonal conditions, as a useful approach for understanding help-seeking, arises from a basic understanding of the way in which people interrelate. That interrelation can provide psychological and physiological resources, which in turn will allow them to be healthy and competent in what they are trying to accomplish (e.g., Heaphy \& Dutton, 2008; Rousseau \& Ling, 2007). In other words, high quality interrelating can create more positive psychological states that facilitate an optimal level of functioning (Vinarski-Peretz, Binyamin, \& Carmeli, 2011). 
A focus on how interpersonal conditions facilitate action is theoretically and practically important because help-seeking in work organizations involves taking personal initiative and is an effortful interpersonal action (Lee, 2002). A subordinate's help-seeking efforts are shaped, in part, by how supervisors treat them. However, in many work organizations supervisors-or people with formal or informal power over others-can open up or shut down an employee's initiative-taking, as they are pivotal actors in encouraging or discouraging these forms of discretionary behaviors.

Thus, a key question our study addresses is: how can supervisors encourage subordinates to seek professional help through their interactions with their subordinates? Our focus on how supervisors interact with their subordinates comes from a basic interest in the power of respectful engagement. Respectful engagement is a form of interaction that we know is important from a variety of relational theories. Our hypotheses are grounded in ideas drawn from the relational model of authority (Smith, Tyler, \& Huo, 2003; Tyler \& Lind, 1992), group value model (Smith, Tyler, Huo, Ortiz, \& Lind, 1998), group engagement model (Tyler \& Blader, 2000), and social valuing perspective (Dutton, Debebe, \& Wrzesniewski, 2015). Together these models contribute to building an overall logic for the importance of respectful interactions with supervisors in order to explain a subordinate's help-seeking from coworkers, thereby enhancing task performance. We call this integrative logic a "relational resourcing theory," suggesting that positive forms of interacting at work (such as respectful engagement) are generative (i.e., resource-producing) conditions that enhance an individual's capacities for discretionary behaviors, like help-seeking. When help-seeking increases, this form of proactive behavior contributes to greater task performance. 
We further seek to understand the relational conditions that facilitate help-seeking. We suggest that the psychological and social bolstering that emerge when supervisors interact with subordinates in respectful ways is particularly important when employees do not feel psychologically safe. Low levels of psychological safety imply that individuals are unable to completely show and employ their full selves, nor take interpersonal risks because of the fear of negative repercussions (Edmondson, 1999; Kahn, 1990). Therefore, our study contributes to a better understanding of the context in which help-seeking is enacted (Geller \& Bamberger, 2012). We attempt to do so by shedding light on how and when a supervisor's respectful interactions with subordinates facilitate help-seeking, thereby contributing to job performance at work.

\section{Theory and Hypotheses}

\section{The Importance of Respectful Engagement}

A relational perspective-which focuses on the ways people treat others or how people react to others' actions towards them-has long been a key subject of inquiry in organizational behavior, and more specifically in human relations. In pursuing this line of research, scholars have built and expanded on the relational model of authority (Smith et al., 2003; Tyler \& Lind, 1992), the group value model (Smith et al., 1998), and the group engagement model (Tyler \& Blader, 2000). All of those conceptual frameworks apply a justice perspective on respect to one's interaction with other persons (i.e., whether one treats another person fairly such that he or she feels respected). Conceptualizations of respect vary from respect as a cognitive "social evaluative feedback from the group" (i.e., perceived status; Blader \& Tyler, 2009; Tyler \& Smith, 1999), to respect as an affective valuation (i.e., perceived liking; Branscombe et al., 2002) (In: Huo et al., 2008). In either case, respect involves the perception of one person's treatment of 
another. While perceived respect-defined as "an individual's assessment of how they are evaluated by those with whom they share common group membership"-is important (Huo et al., 2008, p. 1571), it is often created not by one's formal position but through particular forms of interpersonal treatment during interaction. We call these particular forms of interpersonal treatment that create respect, "respectful engagement" (Dutton, 2003). The kinds of behaviors that capture "doing respect in interaction" include, "being present to others, affirming them, communicating and listening in a way that manifests regard and an appreciation of the other's worth" (Dutton, 2003, p. 22). We see respectful engagement as a pattern of interactions marked by behaviors that convey positive regard (Rogers, 1957), appreciation, and a sense worthiness of others (Goffman, 1967; see also Grover, 2014; Rogers \& Ashforth, 2015). We suggest that respectful engagement captures the substance and essence of interpersonal interaction, fundamentally creating conditions that resource individuals to engage.

It is argued that respectful interactions are generative in the sense that these ways of interaction produce psychological and behavioral resources (e.g., greater energy and confidence, and capability to act), and are an important means for facilitating members' eagerness and capabilities for discretionary action (Dutton, 2003). This assertion is consistent with the group value model (Smith et al., 1998) and the group engagement model (Blader \& Tyler, 2009; Tyler $\&$ Blader, 2000). That consistency suggests that when people are treated with respect, they develop a sense of being valued in a group and develop a more positive view of themselves, which builds confidence and motivates discretionary behaviors. For example, research has shown that perceived respect is positively related to one's perceived value in a team as it will increase their willingness to invest in team-related efforts (Ellemers, Sleebos, Stam, \& Gilder, 2013). Similarly, studies indicate that when a group communicates respect towards members, 
they feel included and accepted, and thus, more willing to engage and contribute (De Cremer, 2002). These theories also suggest that experiencing respect from others augments feelings of social inclusion, which empowers people to reciprocate and invest efforts that go beyond formal expectations (see also Huo \& Binning, 2008). For example, deliberative universalism suggests that when individuals respect each other's views and values (i.e., form mutually respectful relationships), it develops a sense of common ground, and resources individuals to see new possibilities for overcoming differences (Gutmann, 1993).

We posit that respectful engagement is a relational resourcing mechanism that empowers individuals to seek professional help at work. Respectful engagement sends a signal of welcome and acceptance within a social group that resource individuals to approach others and seek their help. In particular, we suggest that when people interact in a respectful way, it can send messages of acceptance to the other person, which in turn can bolster their social inclusion and self-worth. A sense of inclusion and worthiness are psychologically strengthening in terms of boosting confidence (Bandura, 1986; Shamir, House, \& Arthur, 1993) and reducing anxiety (Dutton \& Heaphy, 2003). Further, senses of inclusion and worth are forms of positive self-meaning. A potent form of positive self-meaning takes place when people feel as though they are significant in the eyes of others (Wrzesniewski, Dutton, \& Debebe, 2003). Psychologists suggest that positive self-meanings, like "I am included and a part" or "I am worthy," psychologically resource people with higher levels of self-confidence and efficacy (e.g., Steele, 1998). In turn, those higher levels of confidence and efficacy empower them to act and adapt (see also Carmeli, Jones, \& Binyamin, 2016). Organizational researchers suggest that positive self-meanings, created in interaction with others, are part of a more general social valuing process. The theory of social valuing at work suggests that everyday interactions with others at work, whether positive 
or negative, compose a sense of self-worth on the job that either enhance or diminish resources for doing work (Dutton et al., 2015). However, we hypothesize that respectful engagement is a resourcing mechanism that is particularly important in hierarchical relationships, such as between supervisors and subordinates.

\section{Respectful Engagement with Supervisors}

A relational model of authority theorizes that the ways in which an authority figure reacts to and treats their subordinates, affects how subordinates perceive the group and themselves, as well as consequently shapes their levels of engagement (Tyler \& Lind, 1992). Supervisors- who generally have greater degrees of power and status than the people below them-are prone to the biases of power that can reduce their attentiveness to the less powerful (See, Morrison, Rothman, \& Soll, 2011), constrict levels of empathic concern toward the conditions of others (van Kleef, Oveis, van der Lowe, LuoKogan, Goetz and Keltner, 2008), and increase the amount of selfserving attributions (Kipnis, 1972). The aforementioned biases, which plague people with greater power, tend to restrict behaviors from lower-power subordinates, such as help-seeking, because subordinates are concerned that they are being judged. Accordingly, in such hierarchical relationships, seeking help would be perceived as a sign of incompetence. However, respectful engagement between supervisors and employees would be particularly important to empower subordinates to seek help at work. Not only would it help alleviate concerns for potential help seekers, but it could also help build psychological resources that would enable employees to seek help from higher-ranked authorities and from their peers.

Specifically, respectful engagement allows members to feel included in a group. Their sense of worth in the group builds their confidence and efficacy, which fuels seeking help from other coworkers and supervisors alike. The relational model of authority informs us that when 
subordinates are treated by authorities in a more respectful and fair way, they feel more comfortable to engage in discretionary behaviors (Tyler \& Lind, 1992). Additionally, they will engage in behaviors that help the group (Huo, Binning, \& Molina, 2010a), citizenship behaviors (Huo, Binning, \& Molina, 2010b), and help-seeking. Thus, instrumentally and symbolically, respectful engagement with "higher ups" can be an important relational mechanism that fosters proactive discretionary behaviors, like help-seeking. For example, a study of prisoners revealed that lower power prisoners sought help from doctors and other healthcare professional, who held power over prisoners, when they believed these authority figures were treating them with respect (Howerton, Byng, Campbell, Hess, Owens, \& Aitken, 2007). This leads to the following hypothesis:

Hypothesis 1: Respectful engagement with one's supervisor is positively related to employee help-seeking behaviors.

\section{Help-Seeking Behaviors and Job Performance}

Help-seeking is a key mechanism through which individuals and groups find solutions for ill-defined problems (Hargadon \& Bechy, 2006, p. 490). It is the type of behavior that fosters the learning and acquiring of new skills and disciplines (Morrison, 1993), boosts knowledge capability (Leonard-Barton, 1989), promotes information transfer through network ties and cooperation (Nadler, Ellis, \& Bar, 2003), motivates colleagues to come up with new ideas (Allen, 1977), improves problem solving, (Morrison, 1993), facilitates creativity (Mueller \& Kamdar, 2011), and encourages faster decision making (Eisenhardt, 1989).

Drawing on this literature, we specify multiple reasons why employees who engage in help-seeking behaviors are more likely to exhibit improved performance. First, seeking professional help makes people more aware of their situation and the context in which things are 
done. Second, seeking help facilitates the learning process, expands knowledge competency and problem-solving capacity (Ellis \& Tyre, 2001, Lee, 1997; Leonard-Barton, 1989; Morrison, 1993; Van Ginkel \& Van Knippenberg, 2008), and drives faster quality decisions (Eisenhardt, 1989). Third, when individuals seek help they often ask for both task-related information and confirmations of previous work. The combination of both allows individuals to develop a more nuanced understanding of the task-at-hand, ultimately facilitating greater task mastery and higher performance (Butler, 1993; Newman, 1998). Fourth, help-seeking behaviors create greater role clarity (Whitaker \& Levy, 2012). Greater role clarity reduces uncertainty regarding the tasks and helps develop a better grasp of the factors involved in a particular work process or issue (Morrison, 1993). Fifth, when employees seek help they develop a better understanding of their supervisors' and coworkers' expectations. That better understanding helps expand their sensemaking concerning how a task should be carried out, which contributes to improved task performance (Morrison, 1993). Sixth, when work is highly interdependent, help-seeking behaviors are likely to facilitate greater cooperation between people, an essential dynamic for solving complex tasks (Bamberger, 2009). Finally, we suggest that when employees seek help from supervisors and coworkers, they develop higher self-efficacy, which social cognitive theorists believe is a major mechanism for enhancing performance (Bandura, 2001). This logic leads to our second hypothesis.

Hypothesis 2: Help-seeking behaviors are positively associated with employee job performance.

\section{The Role and Implications of Respectful Engagement}

Although we posit a positive influence of help-seeking behaviors on job performance, we highlight the relational and socio-psychological contexts, which allow members to seek help that 
can equip them with knowledge and expertise and are key to performing at higher levels. Specifically, we suggest a moderated-mediation model in which respectful engagement between supervisors and their employees facilitates help-seeking behavior, and thereby enhances job performance. However, we argue that respectful engagement is particularly vital for employees with low-levels of psychological safety. We first theorize about the mediating relationships among respectful engagement, help-seeking, and job performance, followed by a discussion of the moderating role of psychological safety.

\section{Respectful Engagement, Help-Seeking Behaviors, and Job Performance}

When supervisors treat employees with a sense of respect, they not only send a signal of social inclusion and affirm their sense of worth (Smith et al., 1998, 2003; Tyler \& Lind, 1992), but also relationally resource them (Dutton et al., 2015) to seek and give professional help. In addition, when respectful engagement is pervasive, help-seekers are likely to be less concerned about potential image loss in the help-seeking process (Lee, 1997). When these forms of positive interrelating exist at work, people are more likely to invite and exchange inputs with each other (Carmeli, Dutton, \& Hardin, 2015).

Help-seeking behaviors, in turn, can boost employee performance at work. By seeking professional help, employees are better equipped to solve work-related problems. They are better equipped because they are better able to draw on others' expertise and build on unique views, such that a better solution is likely to emerge. In addition, help-seekers can develop a better understanding of the tasks, as well as accessing resources (e.g., knowledge, networks) that would not have been available without their help-seeking efforts (Whitaker \& Levy, 2012). The greater availability and use of resources, as well as the development of greater clarity about the situation and context, are likely to facilitate better performance. This leads to the following hypothesis: 
Hypothesis 3: Respectful engagement with one's supervisor is indirectly, through helpseeking behaviors, related to employee job performance.

The Moderating Role of Psychological Safety

An employee's fundamental concern in asking for help from others at work arises from the psychological cost of potential image loss (Lee, 1997). This suggests that employees need a climate where they are not afraid of exposing their lack of knowledge or capabilities (Bennet \& Lehman, 2001). Employees also need a climate where they are encouraged to engage (Kahn, 1990). Research suggests that people are likely to avoid asking for help when they feel less psychologically safe, particularly from higher authority figures who have the capacity to judge their behaviors (Edmondson, 2004). Psychological safety is "experienced as the feeling of being able to show and employ one's self without fear of negative consequences to self-image, status or career" (Kahn, 1990, p. 708). Psychological safety also taps one's perceptions of whether it "is safe for interpersonal risk-taking" (Edmondson, 1999, p. 350). Psychological safety and respectful engagement are conceptually related constructs as they both tap interpersonal experiences. However, respectful engagement outlines conditions in which people can either feel psychologically safe or unsafe in an interpersonal context. Psychological safety is about feeling able to express oneself (Kahn, 1990, p. 708), whereas respectful engagement refers to ways people interrelate with each other that build quality relationships. ${ }^{1}$

\footnotetext{
${ }^{1}$ Psychological safety and respectful engagement with a superior, while related, can also operate independently. For example, an employee might experience respectful interactions with his or her supervisor, but feel psychologically unsafe because he or she did not establish positive work relationships with co-workers. We know that sometimes an employee establishes close ties with his or her supervisor, but this relationship does not translate into the experience of psychological safety at work. In this case, fellow employees could become envious of this co-worker and see him or her as the supervisor's "favorite." In this case, the person who enjoys a respectful relationship with their supervisor may feel psychologically unsafe because co-workers may work to diminish the special status of the "favored one." This is one example of several possible scenarios where respectful engagement with supervisors is decoupled from a sense of psychological safety at work.
} 
Our theorizing suggests that respectful engagement between supervisors and employees is particularly important for help-seeking from organizational members when employees feel psychologically unsafe at work. When employees feel a low level of psychological safety, they are more likely to be vigilant about cues and deeds from higher ups that would send clear messages of acceptance, appreciation, and worthiness. Employees in this kind of psychological state may experience an even greater need for interactions with authority figures that would resource them for approaching and help-seeking from others. We reason that when supervisors treat subordinates who do not feel psychologically safe with respect, they address the needs for inclusion and feeling valued. Accordingly, they create conditions that help alleviate the insecurities associated with low levels of psychological safety. At the same time, respectful engagement makes it easier for the employees who feel psychologically unsafe to engage in behaviors that may put them at interpersonal risk. In this kind of transitional state, they are more likely to feel comfortable seeking access to others for help. Relational processes like respectful engagement with supervisors are likely to reduce members' insecurities and resource them to engage in help-seeking behaviors. In turn, their job performance would enhance. This leads to the following hypothesis:

Hypothesis 4: Psychological safety moderates the indirect relationship between respectful engagement between employees and their supervisors and job performance; the indirect link between respectful engagement and job performance through help-seeking behaviors is stronger for employees who feel a low level of psychological safety.

\section{Method}

\section{Sample and Procedure}


We approached fifteen small- to medium-sized organizations in Israel and asked the CEOs or Human Resources Directors to have their companies participate in this study. The organizations were from a variety of fields, including software and hardware companies, manufacturing companies, an accounting services firm (i.e., CPA firm), and a non-formal educational service firm for youth. We chose to focus on these organizations because their work contexts are highly interdependent and because they operate in a variety of industries (Cook \& Campbell, 1979). Two organizations chose not to participate: one organization expressed that they do not want to engage in the study, and the other declined our request to survey both employees and supervisors. We gathered together the remaining organization and gave a short presentation in which we solicited their involvement, ensured respondents full confidentiality, and made clear that the collected data would only be used for our research.

Subsequently, we received access to lists of employees and their direct managers (supervisors). The participants completed the questionnaires voluntarily and without compensation. In total, we accessed 300 employees and their supervisors. However, because we administered and collected surveys from the employees and supervisors on site, 40 employees were absent during the days that the first author visited the organization to collect the data on respectful engagement and psychological safety. As a result, we administered and collected 260 surveys at T1. A month later (T2), we asked the same 260 employees to complete the second part of the survey on help-seeking seeking behaviors and job performance. We received 251 usable surveys, for an attrition rate of less than 4 percent. We asked the participants' direct supervisors (19 in total) to fill out a short questionnaire about the performance of their subordinates. Of the 251 participants, $67 \%$ had a bachelor's degree or above, $24 \%$ had a technical engineering degree, and $9 \%$ had a high school diploma. Ages ranged from 20 to 69 , with an average of 39.53 (SD, 
9.58), and $73 \%$ were between the ages of 30 and 49 . Fifty-one percent had been with the organization for up to 5 years. The participants' professional experience ranged from 0 to 40 years, with an average of 11.72 (SD, 7.98), and 51\% had professional experiences of 5 to 15 years.

\section{Measures}

With the exception of the performance measure, all measures were assessed on a scale ranging from 1 (not at all) to 5 (to a very large extent).

Employee job performance. Using four items from Black and Porter's (1991) scale (we did not use the item "ability to get along with others" because it did not capture the essence of task performance being studied here), we asked supervisors to assess their subordinates' job performance. We adapted the items to fit supervisory-rating performance. A sample item is: "this employee (Name) completes his/her tasks on time." Responses were on a five-point Likert scale from 1 = "significantly worse than other employees" to $5=$ "significantly better than other employees." $(\alpha=.78)$.

Help-seeking behaviors . Based on previous research (Anderson \& Williams, 1996), we constructed three items to assess employee help-seeking behaviors specifically aimed at solving work-related problems. We instructed respondents to reflect on what they do when they encounter a problem in their work. The items included: "When I run into a professional problem in my work, I feel comfortable approaching my coworkers for help," "When I encounter a professional problem, I feel comfortable approaching my supervisor for help and consultation," and "When I encounter a professional problem, I approach both the supervisor and co-workers for professional help at work.” $(\alpha=.84)$. In the pilot studies, we assessed the validity of our measure using two separate pilot studies among full-time employees in Israel and USA in which 
we asked respondents questions about both help-seeking and feedback-seeking behaviors. The findings of 122 employees in Israel indicate that our scale showed good reliability $(\alpha=.83)$. A factor analysis indicates that help-seeking behaviors were distinguished from both Van deWalle, Ganesan, Challagalla, and Brown's (2000) scale, which measures feedback from monitoring and inquiry and Renn and Fedor's scale (2001) that assesses feedback-seeking behaviors. No crossloadings above .30 were observed. The correlations between the measures for help-seeking behaviors and the measures for feedback-seeking behaviors were $.10(p>.10)$ and $.30(p<.05)$. Next, we ran the same pilot study among employees in the USA using MTURK. The findings from 160 American employees indicate that our scale showed reasonable reliability $(\alpha=.76)$. An exploratory factor analysis indicates that help-seeking behaviors were again distinguishable from both Van deWalle et al.'s (2000) scale and Renn and Fedor's scale (2001), which assess feedback-seeking behaviors. No cross-loadings above .30 were observed within the Van deWalle et al.'s measure and only two items of Renn and Fedor's scale reached a cross-loading of .36 and .34. We found a similar pattern of modest correlations $(.05, \mathrm{p}>.10$ and $.30, \mathrm{p}<.05)$ between the measures for help-seeking behaviors and the measures for feedback-seeking behaviors.

Respectful engagement with one's supervisor. We assessed the level of respectful engagement using Carmeli et al.'s (2015) scale which was derived from Dutton's conceptualization of respectful interaction dimensions (Dutton, 2003). We measured respectful engagement between an employee and his or her direct supervisor. Sample items were: "My manager speaks to me in a respectful rather than in a demanding way," "My manager makes requests, not demands from me," and "My manager pays the utmost attention to me and my needs." $(\alpha=.90)$. 
Psychological safety. We assessed employee perceptions of psychological safety using Edmondson's (1999) seven-item scale. A sample item is: "It is fairly safe for me to take risks in the organization.” $(\alpha=.66)$.

Trust. We also wished to include a control measure in our analysis that would allow us to capture whether a social exchange relationship explained levels of help-seeking, Accordingly, we included a measure of peer (collegial) trust in our modeling. A relationship of social exchange taps the reciprocity occurring between people which is typically captured by the level of exchange between two or more people (e.g., Baker \& Dutton, 2007 The level of reciprocity between people allows them to be more or less trusting of each other (see Cropanzano \& Mitchell, 2005). Where more trust exists, we thought it would also contribute to help seeking because trust reflected people's beliefs that others would be honest and protective if they tried to seek help. We assessed trust using Dunn and Schweitzer's (2005) 10-item scale. A sample item is “__ would never intentionally misrepresent my point of view to others". $(\alpha=.83)$.

Additional control variables. We controlled for employee tenure (years of experience in the organization), as it may influence an individual's inclination to seek professional help. We also collected data on the following control variables: age, education, and professional experience field. However, since these controls had no significant influence on the outcome variables we have not included them in subsequent analysis.

\section{Data Analysis}

We employed structural equation modeling (MPlus v. 7.4 software Muthén \& Muthén, 2015) to test a latent variables model.

We first performed a CFA to assess whether the measurement items (indicators) reflected their intended latent variables. However, because using all of the measurement items in the 
survey as indicators "would have resulted in an exceedingly large number of parameters relative to the sample size" (see Graves, Sarkis, \& Zhu, 2013, p. 85) we used parcels of scale items as indicators of the latent variables, a procedure that is appropriate given our interest in examining the relationships between latent variables instead of the attributes of individual scale items (Landis, Beal, \& Tesluk, 2000; Little, Cunningham, Shahar, \& Widaman, 2002) (in Graves et al., 2013, p. 85). Thus, we have randomly selected and used all items in building three parcels per latent variable for assessing both the measurement model and the hypothesized model. CFA goodness-of-fit indices such as $\chi 2$ and $\chi 2$ divided by the degree of freedom $(\chi 2 / \mathrm{df})$, the standardized root mean square residual (SRMR), AIC, the Tucker-Lewis coefficient (TLI), the comparative fit index (CFI) and the root mean square error of approximation (RMSEA) were calculated. We tested the model with and without the moderator psychological safety. Following Fadda and Scalas (2016), as a preliminary test, we examined the measurement model based on correlated latent variables with no structural regression paths nor the interaction variable (psychological safety as a moderator). This 4-factor CFA test was followed by an additional 5factor CFA test in which the moderator psychological safety was added.

The final model included the interactions between the latent variables. We used the LMS (Latent Moderated Structural equations) approach to fit this model. Since the LMS approach does not provide conventional fit indicators for assessing overall model fit, the test for the fit of the model requires the estimation of two models (Muthén, 2012). As a first step, we estimated the structural model without the latent interaction term. This model supplied the model fit indices. At the second step, we estimated the structural model with the latent interaction. For this second model, the only fit indices available in MPLUS are information criteria, such as AIC and 
BIC. We compared the two models using the likelihood ratio test (see also Maslowsky, Jager, \& Hemken, 2015).

In order to help with the interpretation of the interactions, we created an interaction plot for high (+1 s.d.) and low levels (-1 s.d.) of psychological safety (moderator) (Cohen \& Cohen, 1983; Aiken \& West, 1991) and tested the significance of the slopes of the lines in the plot. We also calculated intra-class correlations (ICC) for the dependent variables to evaluate whether belonging to a specific company or organization had an impact on the results.

\section{Results}

Table 1 shows the means, standard deviations and correlations between the research variables. The means, standard deviations and correlations are based on the averages of the items comprising the scales.

--Insert Table 1 about here--

\section{Model Structure}

Four-factor CFA test (without moderator variable Psychological Safety): We performed confirmatory factor analysis (CFA) using MPlus software on the following model variables: help-seeking behaviors, respectful engagement with one's supervisor, Trust and Job performance (supervisory-rating). In order to demonstrate the discriminant validity of the model's constructs, we followed the 4-factor model analysis with a 3-factor model (where helpseeking and job performance were loaded on the same latent variable) and a 1-factor model (where all items were loaded on the same latent variable). The 4-factor model showed the best fit with the data ( $\chi 2$ of 132.29 on 48 degrees of freedom, a RMSEA of .084 and the lowest AIC was obtained). In addition, following Gerbing and Anderson (1988), the results concerning the values of the factor loadings-the construct reliability and variance extracted indicated a good fit with 
the data $($ Help-Seeking $=0.85365,0.66479 ;$ Respectful Engagement $=0.90192,0.75515 ;$ Job Performance $=0.75537,0.51391$; Trust $=0.83180,0.62363$, respectively). CFA demonstrates that the model with the 4 factors had a good fit. The highest correlation was between Job Performance and Help-Seeking (.42). Correlating coefficients with magnitudes between 0.3 and 0.5 indicate variables which have low correlations. After collapsing Job Performance and HelpSeeking into one factor, the model had a poor fit, which became even poorer when all items were loaded onto one factor. The fit statistics are shown in Appendix A.

Five-factor CFA (with moderator variable Psychological Safety ): the correlation between Psychological Safety and Respectful Engagement in the 5-factor model is 0.52. Correlation coefficients whose magnitudes are between 0.5 and 0.7 indicate variables which can be considered moderately correlated. In order to demonstrate the discriminant validity of the psychological safety and respectful engagement constructs the 5-factor model analysis was followed by a 4-factor model (where psychological safety and respectful engagement were loaded onto the same latent variable). The results indicate that the 5-factor model is a better fit than the 4-factor model $(\mathrm{AIC}=6767.529$ for the 5 -factor model vs 6844.929$)$. The fit statistics are shown in Appendix B.

The LMS model fit was tested, as explained above, by running two models. The first model, in which the moderator psychological safety is included but not interacted with respectful engagement, has marginally acceptable fit $(\mathrm{RMSEA}=0.107, \mathrm{CFI}=0.856, \mathrm{SRMR}=0.088)$. The first model's H0 likelihood value is 3322.874 . The H0 likelihood value of the model with the interaction is -3313.502 . Hence our research model without the interaction has a marginally acceptable fit, but the model with the moderator has a better fit with the data $(p<.00008)$. The statistics regarding the model without the interaction are shown in Appendix B, and those for our 
model results are presented in Appendix C. Further, we assessed the potential clustering of employees nested within the same organizations and the same supervisors. We tested for the potential multilevel nature of the data by calculating ICCs for the dependent variables. We estimated ICC1 by calculating the ICC1.lme function of psychometric R library. At the supervisor level, we found that ICC1 was small (practically 0), and non-significant for both constructs. For help-seeking (ICC1 using mixed-models=1.621035e-09), ICC1 = -0.033, p=0.98. For job performance (ICC1 using mixed-models $=0.01902266), \mathrm{ICC} 1=0.003, \mathrm{p}=0.4 \mathrm{We}$ followed this procedure at the organization level and found that ICC values for both help-seeking $(\mathrm{ICC} 1=-0.033, \mathrm{p}=.967$, mixed-models $=8.433148 \mathrm{e}-10)$ and job performance $(0.003, \mathrm{p}=.398$ mixed-models $=1.495127 \mathrm{e}-08$ ) were negligible or even negative. These findings indicate that HLM is unjustified at these (manager/supervisor and organizational) levels.

\section{Research Model and Hypotheses}

The SEM model results are shown graphically in Figure 1 where the ovals represent the latent variables. Only statistically significant links for the model variables are presented. --Insert Figure 1 here--

The positive, significant estimates for the relationships between respectful engagement with one's supervisor and help-seeking behaviors provide support for Hypothesis 1. The positive, significant estimates for the relationships between help-seeking behaviors and job performance support Hypothesis 2.

--Insert Figure 2 here--

\section{The Mediating Role of Help-Seeking Behaviors}

We used the SEM model to test the mediation hypothesis. As shown in Table 2, the direct effect between respectful engagement and job performance (path 3) was not significant. We also 
tested the effect of the number of employees per supervisor, and found no significant effect on the dependent variables in the model. However, on the other hand, the indirect effect of respectful engagement and job performance through help-seeking (path 2) was statistically significant. This pattern of findings lends general support to Hypothesis 3-that help-seeking mediates the link between respectful engagement and job performance.

--Insert Table 2 about here--

\section{The Moderating Effect of Psychological Safety}

The SEM run provided a value of -.749 for the interaction term coefficient with $p<$ .0001 , showing that the interaction is significant. The results, which are illustrated in Figure 2, indicate that for a low level of psychological safety, the slope indicating the relationship between respectful engagements and help-seeking was significant $(.57, p<.001)$. However, this same relationship was insignificant at high levels of psychological safety $(-.172, p=.331)$. The direct effect of respectful engagement on help-seeking was significant when psychological safety was low, and insignificant when psychological safety was high (path 1). The indirect effect between respectful engagement and job performance, through help-seeking, was significant when psychological safety was low, and insignificant when psychological safety was high (path 2). The results with a specified $95 \%$ confidence interval and with 5,000 bootstrap replications were 0.095, 0.413 for the indirect Path 2 at a low level of psychological safety, and $(-0.263,0.053)$ at a high level of psychological safety. Those results support Hypothesis 4.

\section{Discussion}

This paper examined why and how respectful engagement with one's supervisor fosters help-seeking behaviors and enhances job performance. We also assessed the moderating role of psychological safety in this mediated relationship between help-seeking and job performance. 
The findings indicated that when supervisors treat employees with respect, the employees engage in more help-seeking behaviors, which in turn enhances their job performance. Our findings also indicated that these indirect relationships are moderated by psychological safety, such that respectful engagement with supervisors is most important for those who feel psychologically unsafe.

We sought to contribute to the literature on help-seeking behaviors by extending theorizing, derived from relational perspectives, that suggests that how employees react to and treat each other at work shapes their perceptions and behaviors. Our focus here was on helping as a discretionary, pro-social behavior (Podsakoff et al., 2000). Particularly, our focus was on helpseeking behaviors. We endeavored to test the importance of a key mechanism—-the seeking of professional help at work through a focus on interpersonal conditions (Newman, 2006; Lee, 1997, 2002). Through a focused look at respectful engagement with supervisors, we provided a more nuanced understanding of why employees act and seek help at work (Bamberger, 2009; Hofmann et al., 2009; van der Rijt et al., 2013).

Our research also advances the understanding of the conditions under which particular sources are most important for help-seekers so that they may yield the benefits of asking for help at work (Bamberger, 2009; Geller \& Bamberger, 2012). Our study alludes to the importance of the relational context of interrelating in respectful ways and facilitating help-seeking, which in turn, can drive job performance. In what follows, we elaborate on our study's main contributions to theory and research.

Our research drew from and informs relational perspectives, as well as their capacity to address the question-what enables employees to seek help at work? Building on and integrating the Relational Model of Authority (Smith et al., 2003; Tyler \& Lind, 1992), Group Value Model 
(Smith et al., 1998), Group Engagement Model (Tyler \& Blader, 2000), and the Social Valuing Perspective (Dutton et al., 2015), we were able to specify a particularly generative way of interrelating (respectful engagement) that can be instrumental to help-seeking behaviors. We built on the Relational Model of Authority (Smith et al., 2003; Tyler \& Lind, 1992) by elaborating on the idea that the ways in which authorities react to and treat their subordinates is crucial for shaping their perceptions and behaviors. Following further theoretical refinements developed in the Group Value Model (Smith et al., 1998) and in the Group Engagement Model (Tyler \& Blader, 2000), we revealed that that if respect is behaviorally enacted in relationships between supervisors and employees it generates positive implications for one's discretionary behaviors.

We sought to elaborate these theories by integrating a new logic. We derived that new logic from the Social Valuing Perspective (Dutton et al., 2015). Here, we labeled it as a relational resourcing view. Relational resourcing view provides a complementary explanation for the power of positive interrelating. It provides a complementary explanation by suggesting that when this mode of interrelating (respectful engagement) takes place, it helps to produce psychological and physiological resources that enhance an individual's health and capacity for action (Heaphy \& Dutton, 2008; Rousseau \& Ling, 2007; see also Ragins \& Dutton, 2007). Social Valuing Theory (Dutton et al., 2015) and theories of interpersonal sense-making at work (Wresniewski et al., 2003) offer theoretical lenses that are useful in building a case for the power of interrelating respectfully. These lenses point to respectful interactions as a mechanism that has the potential to nourish discretionary and proactive behaviors through expanding psychological and social resources and fueling discretionary behavior such as seeking help at work. 
A focus on respectful engagement is theoretically important because this line of research is in its embryonic stages of development (Dutton, 2003; Rogers \& Ashforth, 2015) and empirical evidence regarding respectful engagement is relatively scarce (Carmeli et al., 2015; Vogus \& Iacobucci, 2016). Further, the relatively limited body of research on respectful interactions indicates, that mutual respect is a key element in cultivating quality communication between members and in improving job performance through better interpersonal role coordination (Gittell, 2002). However, we expand on the Relational Theory of Coordination (Gittell, 2006) by shifting the discussion from role-based relationships-where mutual respect along with other dimensions of quality relationships exist between "work roles" (Gittell, 2012, p. 401)-to a focus on respect between individual participants.

Our theorizing also tapped into the idea that relational mechanisms are instrumental in reducing the potential social costs of discretionary actions, such as the risk to one's image of seeking help at work (Lee, 2002). Considering that supervisors play a key role in fostering employees' discretionary behaviors (Tyler \& Lind, 1992), their high degree of power and status often leads to inadequate treatment (from lack of support and care to abusive behaviors) of people who do not have similar levels of power (See et al., 2011). Clearly, this can impede subordinates with lower levels of power to seek professional help because these discretionary behaviors sometimes are perceived as signals of incompetence.

However, recent research challenges the aforementioned view regarding the effect of supervisors with a high degree of power and status on help-seeking. The research suggests that in some conditions, help-seekers can be perceived as competent (Brooks et al., 2015). Further, this line of thinking points to the workplace context in which help-seeking is enacted and when seeking help can aid the help seeker to achieve high job performance (Geller \& Bamberger, 
2012). Our research helps explain why the relational context of respect is particularly important for some help-seekers and not important for others in regard to the improvement of their performance. For example, we know that the power of supervisors is high because of their capacity to judge subordinates' behaviors, but we have shown that influence of supervisors can be particularly potent for subordinates who feel psychologically unsafe. It is these subordinates who are most likely sensitive to cues of inclusion and worth, which would prompt interpersonally risky help-seeking behaviors (see Edmondson, 2004).

Scholars have long specified psychological safety as an important socio-psychological condition for personal engagement (Kahn, 1990). We built on this research by showing that respectful engagement between supervisors and employees is particularly important for employees who experience low levels of psychological safety. We advance the literature by explaining why respectful engagement is so important in these conditions. We then supported this explanation empirically. These findings get at the heart of the argument-that respect engenders psychological resources necessary for employees to seek help.

Our findings are even more interesting as they point to the power of respectful engagement in help-seeking, even after controlling for effects of trust. This finding is crucial because it suggests that while trust helps to alleviate an employee's concerns about exposing limitations, such as inferiority and incompetence (Bamberger, 2009), the day-to-day respectful interactions between supervisors and their employees are also crucial in prompting help-seeking.

Finally, this study contributes to the growing body of literature that seeks to understand why people ask for professional help and how this act influences their job performance (Bamberger, 2009; Whitaker \& Levy, 2012). Our focus was on work-related problems for which individuals were seeking help and, more importantly, on the context in which this behavior can 
be instrumental for improving job performance (Mueller \& Kamdar, 2011). This endeavor allows for a better understanding of why and when people engage in help-seeking behaviors. It also allows for a better understanding of how the relational context of respect is vital for those who feel less psychologically safe to seek professional help and utilize it for improving their performance at work.

\section{Practical Implications}

Supervisors and leaders should pay greater attention to how they interrelate with others and how this enables the discretionary actions of those below them. Managers can work to become role models of respectful interactions with subordinates. For example, leaders might deliberately work to become more psychologically present when interacting with subordinates, exhibit more effective listening, and develop a more civil approach that preserves and enhances subordinates' sense of dignity and worth. Another way to foster respectful engagement between supervisors and their employees would be to focus on cultivating a collective climate in which people treat each other with respect. For example, supervisors could work to develop norms for interaction in meetings that deliberately cultivate a more general sense of interpersonal respect (e.g., respecting the time of others, emphasizing the importance of attending when others speak, and expressing verbally and physically that other persons' opinions and ideas are appreciated and welcomed). When a respectful climate becomes part of an organization's culture, it can a strategic asset that opens up help-seeking between people, facilitating greater capacity for learning and adaptability.

\section{Limitations and Future Research Directions}

Our research is not without limitations, and thus caution is called for when interpreting the results. One limitation involves the size of the organizations in our sample. We focused on 
small- to medium-sized organizations. It may be that in larger organizations the paths through which authority figures treat subordinates is more complex.

In addition, our sample organizations operate in Israel. We believe that there may be significant differences across countries with regard to norms of help-seeking behaviors in the workplace. Also, social norms may vary from one organization to the other. Thus, future research should more specifically examine the variability in help-seeking behaviors arising from social norms. Furthermore, we call for caution in generalizing our findings since our sample was based on personal connections of the first author, which potentially created bias in the selection of organizations and respondents associated with convenience sampling.

We assessed respectful engagement and help-seeking behaviors using employee perceptions. Although this is justifiable, we cannot rule out potential biases associated with single source data (Spector, 1994). However, we were able to separate the data collection using a lag of one month. Therefore, we were able to reduce the problem of potential common method bias (Podsakoff, MacKenzie, \& Podsakoff, 2012).

We also encourage reservations regarding supervisory-ratings of job performance. Although such an evaluation is considered more objective than employees' self-assessments (Black \& Porter, 1991), there is a potential for subjectivity since this type of assessment is influenced by factors such as variability in supervisors' judgments, the level of familiarity with employees, their assessment practices, and their personality. Further, we think that our measure of help-seeking has the possibility of being refined to separate feelings of being comfortable in asking for help, instead of actual help-seeking behaviors. Perfecting a measure of help-seeking would open up new possibilities to study the effect of respectful engagement on people who feel more or less comfortable seeking help as well as help distinguish respectful engagement from 
actual help-seeking behavior. We acknowledge the relatively low reliability for psychological safety in our study and encourage a constructive replication of the model using different measures of this construct. We also acknowledge that we only implied that resources can be expanded through respectful interactions but did not actually testwhether they have been expanded.

Future research should also consider unobserved variables. There are surely unexplained variables involved in explaining help-seeking behaviors. For example, we underscored the importance of respectful engagement in fostering help-seeking behaviors, but did not specify or measure the emotional mechanisms that might assist in explaining why and how this link occurs. It may be that respect in interactions with supervisor can lessen negative emotions, such anger, or boost positive emotions, such as gratitude. We believe that integrating emotions into models of respectful engagement and behavior could open new windows of opportunity to better understand how emotions developed and regulated.

We also believe that relationships theory would be enhanced if researchers considered focusing on respectful engagement. Such deliberation, with respectful engagement in mind, would help us to consider downstream impacts (e.g. when person A enjoys respectful interactions with person $\mathrm{B}$, but not with person $\mathrm{C}$ ). We think that this is an important issue. We only touched on it here to provide some insights regarding why respectful engagement with one's supervisor is particularly important for an employee who feels less psychologically safe in a work environment. Following recent research (Golan \& Bamberger, 2005; Grodal et al., 2015) future research may explore the importance of relational engagement in the unfolding conditions of help seeking and help-giving processes. 
Further, we can envision other related theoretical lenses and concepts that may further the understanding of core mechanisms at work in our model. For example, relational leadership and social identity scholars suggest that one's identification with his or her supervisor (i.e., relational identification) translates into more or less desired behaviors (Sluss \& Ashforth, 2007; Stephens \& Carmeli, 2017). Although, when developed into a form of over-identification, relational identification can lead employees to engage in undesirable behaviors and perform less effectively.

For example, when a hypothetical employee, John, identified with his or her supervisor it made him more engaged and helped him achieve higher performance. However, co-workers developed a different perception about the relationship between John and his supervisor over time. John's strong identification with Jack, his supervisor, grew over time such that John shared the same norms and beliefs as Jack. Nevertheless, when Jack's opinions were challenged by other colleagues, John felt that it was also a threat to his own identity. Therefore, he escalated his identification with Jack. In this case, the extensive relational identification with his supervisor did not allow John to see opportunities to seek help from others (who challenged Jack's beliefs). In turn, the extensive relational identification made it difficult for John to perform his tasks effectively. Scholars have noted the potential risks that over-relational identification can create for undesirable behaviors, such as workplace dishonesty (Leavitt \& Sluss, 2015). We believe that there is an opportunity for scholars to develop and empirically test the conditions in which respectful engagement and relational identification produce more or less desirable behaviors and outcomes.

Another future research path that is worth pursuing is the question-how do respectful interactions with supervisors emerge and develop over time? On the one hand, we want to know 
how respect between people can be cultivated, and on the other hand we need to better understand how to handle disrespectful interactions. This is an interesting theoretical question with practical implications. If managers can know what should be done in both scenarios, they can build an organization where more extensive help-seeking is probable.

In addition, even if we consider job performance as an omnibus construct, our data cannot rule out the possibility that high performers may develop greater confidence to seek help when needed. However, we assume that even when individuals perform well they may still be reluctant to seek help from those who do not treat them respectfully. We encourage further research because high and low performers may apply different processes when they seek help. Thus, expanding our model to assess these conditional effects of high and low performers in the link between help-seeking and job performance would be a useful future research project.

\section{Conclusion}

Because individuals spend many hours in the workplace, they will more than likely encounter problems that require seeking help from organizational members. However, they often avoid asking for professional help because of the potential negative repercussions to their image and because of the effort that help-seeking can involve. This paper builds on relational perspectives. It also develops a relational resourcing view to explain how the interactions of supervisors and employees can resource employees to engage in discretionary action, like helpseeking behaviors. Our relational resourcing theory spotlights the potency of respectful engagement in fostering help-seeking behaviors for those with low levels of psychological safety. Our theory also highlights that seeking help improves job performance. Our hope is that this endeavor will attract further research on the power of interrelating in a respectful way at 
work, as well as the mechanisms through which it can facilitate processes and enhance performance outcomes. 


\section{References}

Aiken, L. S., \& West, S. G. (1991). Multiple regression: Testing and interpreting interactions. Newbury Park, London: Sage.

Allen, J. T. (1977). Managing the flow of technology. Cambridge, MA: MIT.

Anderson, S. E., \& Williams, L. J. (1996). Interpersonal, job and individual factors related to helping processes at work. Journal of Applied Psychology, 81, 282-296.

Baker, W., \& Dutton, J. E. (2007). Enabling positive social capital in organizations. In J. E. Dutton \& B. R. Ragins (Eds.), Exploring positive relationships at work: Building a theoretical and research foundation (pp. 325-345). Mahwah, NJ: Erlbaum.

Bamberger, P. A. (2009). Employee help-seeking: Antecedents, consequences and new insights for future research. In J. J. Martocchio \& H. Liao (Eds.), Research in personnel and human resources management (Vol. 28) (pp. 49-98). Bingley, UK: Emerald Group Publishing.

Bandura, A. (1986). Social foundations of thought and action: A social cognitive theory. Englewood Cliffs, NJ: Prentice Hall.

Bandura, A. (2001). Social cognitive theory: An agentic perspective. Annual Review of Psychology 52(1): 1-26.

Bennet, J. B., \& Lehman, W. E. (2001). Workplace substance abuse prevention and helpseeking: Comparing a team-oriented and informational training. Journal of Occupational and Health Psychology, 6 (3), 243-254.

Black, J. S., \& Porter, L. W. (1991). Managerial behaviors and job performance: A successful manager in Los Angeles may not succeed in Hong Kong. Journal of International Business Studies, 22 (1), 99-113.

Branscombe, N. R., Spears, R., Ellemers, N., \& Doosje, B. (2002). Intragroup and intergroup evaluation effects on group behavior. Personality and Social Psychology Bulletin 28: 744-753.

Brooks, A. W., Gino, F., \& Schweitzer, M. E. (2015). Smart people ask for (my) advice: Seeking advice boosts perceptions of competence. Management Science, 6, 1421-1435.

Butler, R. (1993). Effects of task- and ego-achievement goals on information seeking during task engagement. Journal of Personality and Social Psychology, 65, 18-31. 
Carmeli, A., Dutton, J. E., \& Hardin, A. E. (2015). Linking respectful engagement, relational information processing, and creativity among employees and teams. Human Relations, 68, 1021-1047.

Carmeli, A., Jones, C. D., \& Binyamin, G. (2016). The power of caring and generativity in building strategic adaptability. Journal of Occupational and Organizational Psychology 89(1), 46-72.

Cohen, J., \& Cohen, P. (1983). Applied multiple regression / correlation analysis for the behavioral sciences. Hillsdale, NJ: Erlbaum.

Cook, T. D., \& Campbell, D. T. (1979). Quasi-experimentation: Design and analysis issues for field settings. Boston, MA: Mifflin Company.

Cropanzano, R., \& Mitchell, M. S. (2005). Social exchange theory: An interdisciplinary review. Journal of Management, 31(6), 874-900.

De Cremer, D. (2002). Respect and cooperation in social dilemmas: The importance of feeling included. Personality and Social Psychology Bulletin 28(10), 1335-1341.

Dessler, G., (2008). Human resource management. Upper Saddle River, NJ: Pearson.

Dovidio, J. F., Piliavin, J. A., Schroeder, D. A., \& Penner, L. A. (2006). The social psychology of prosocial behavior. Mahwah, NJ: Erlbaum.

Dunn, J. R., \& Schweitzer, M. E. (2005). Feeling and believing: The influence of emotion on trust. Journal of Personality and Social Psychology, 88 (5), 736-748.

Dutton, J. E. (2003). Energize your workplace: How to create a sustain high-quality connections at work. San-Francisco: Jossey-Bass.

Dutton, J.E., Debebe, G., Wrzesniewski, A. (2015). Being valued and devalued at work: a social valuing perspective. In K. Elsbach \& B. Betchky (Eds.), Qualitative organizational research: Best papers from the Davis conference on qualitative research (Vol. 3).

Charlotte, NC: Inf. Age.

Dutton, J. E., \& Heaphy, E. D. (2003). The power of high-quality connections. In K. S. Cameron, J. E. Dutton, \& R. E. Quinn (Eds.,), Positive organizational scholarship: Function of a new discipline (pp. 263-278). San-Francisco: Berrett-Koehler Publishers.

Dutton, J. E., \& Ragins, B. R. (2007). Moving forward: Positive relationships at work as a research frontier. In B. R. Ragins \& J. E. Dutton (Eds.), Exploring positive relationships 
at work: Building a theoretical and research foundation (pp. 387-400). Mahwah, NJ: Lawrence Erlbaum Associates.

Dutton, J. E., Roberts, L. M., \& Bednar, J. (2010). Pathways for positive identity construction at work: Four types of positive identity and the building of social resources. Academy of Management Review, 35 (2), 265-293.

Edmondson, A. (1999). Psychological safety and learning behavior in team work. Administrative Science Quarterly, 44 (2), 350-383.

Edmondson, A. (2004). Psychological safety, trust and learning in organizations: A group level lens. In R. M. Kramer \& K. S. Cook (Eds.), Trust and distrust in organizations: Dilemmas and approaches (pp. 239-275). New York: Russel Sage Foundation.

Eisenhardt, K. (1989). Making fast decisions in high-velocity environments. Academy of Management Journal, 32, 543-576.

Ellemers, N., Sleebos, E., Stam, D., \& Gilder, D. (2013). Feeling included and valued: How perceived respect affects positive team identity and willingness to invest in the team. British Journal of Management, 24 (1), 21-37.

Ellis, S., \& Tyre, M. J. (2001). Helping relations between technology users and developers: vignette study. IEEE Transactions on Engineering Management, 48 (1), 56-69.

Fadda, D., \& Scalas., F. L. (2016). Neuroticism as a moderator of direct and mediated relationships between introversion-extraversion and well-being. Europe's Journal of Psychology 12(1), 49-67. doi:10.5964/ejop.v12i1.985

Geller, D., \& Bamberger, P. A. (2012). The impact of help seeking on individual task performance: the moderating effect of help seekers' logics of action. Journal of Applied Psychology, 97(2), 487-497.

Gerbing, D., \& Anderson, J. (1988). An updated paradigm for scale development incorporating unidimensionality and its assessment. Journal of Marketing Research, 25, 186-192.

Gino, F., \& Schweitzer, M. (2008). Blinded by anger of feeling the love: How emotions influence advice taking. Journal of Applied Psychology, 93 (5), 1165-1173.

Gittell, J.H. (2006). Relational coordination: Coordinating work through relationships of shared goals, shared knowledge and mutual respect. In O. Kyriakidou, \& M. Ozbilgin (Eds.), Relational perspectives in organizational studies: A research companion (pp. 74-94). Edward Elgar Publishers. 
Gittell, J.H. (2002). Coordinating mechanisms in care provider groups: Relational coordination as a mediator and input uncertainty as a moderator of performance effects. Management Science, 48(11), 1408-1426.

Goffman, E. (1967). Interaction ritual: Essays on face-to-face behavior. New York: Doubleday Anchor.

Golan, M. E., \& Bamberger, P. A. (2015). Mapping the emergent choreography of assistance: The dynamics of dyadic peer helping relations in organizations. Academy of Management Discoveries, 1(2), 124-149.

Grant, A. M., \& Patil, S. V. (2012). Challenging the norm of self-interest: Minority influence and transitions to helping norms in work units. Academy of Management Review, 37, 547568.

Graves, L. M., Sarkis, J., \& Zhu, Q. (2013). How transformational leadership and employee motivation combine to predict employee proenvironmental behaviors in China. Journal of Environmental Psychology, 35, 81-91.

Grodal, S., Nelson, A. J., \& Siino, R. M. (2015). Help-seeking and help-giving as an organizational routine: Continual engagement in innovative work. Academy of Management Journal, 58 (1), 136-168.

Grover, S. L. (2014). Unraveling respect in organization studies. Human Relations, 67 (1), $27-$ 51.

Gutmann, A. (1993). The challenge of multiculturalism in political ethics. Philosophy \& Public Affairs 3(22), 171-206.

Hargadon, A. B., \& Bechy, B. A. (2006). When collections of creative become creative collectives: A field study of problem solving at work. Organization Science, 17 (4), 484500.

Heaphy, E. D., \& Dutton., J. E. (2008). Positive social interactions and the human body at work: Linking organizations and physiology. Academy of Management Review 33(1): 137-162.

Hofmann, D. A., Lei, Z., \& Grant, A. M. (2009). Seeking help in the shadow of doubt: the sensemaking processes underlying how nurses decide whom to ask for advice. Journal of Applied Psychology, 94 (5), 1261-1274. 
Howerton, A., Byng, R., Campbell, J., Hess, D., Owens, C., \& Aitken., P. (2007). Understanding help seeking behavior among male offenders: qualitative interview study. BMJ, 334(7588), 1-7.

Huo, Y. J., \& Binning., K. R. (2008). Why the psychological experience of respect matters in group life: An integrative account. Social Psychology and Personality Compass, 2, 1570 1585

Huo, Y. J., Binning, K. R., \& Molina, E. (2010). Testing an integrative model of respect: Implications for social engagement and well-being. Personality and Social Psychology Bulletin, 36 (2), 200-212.

Huo, Y. J., Binning, K. R., \& Molina, E. (2010b). The interplay between fairness and the experience of respect: Implications for group life. In E. A. Mannix, M. A. Neale \& E. Mullen (Eds.) Research on managing groups and teams: Fairness and groups (Vol. 13) (pp. 95-120). Bingley, UK: Emerald Group Publishing Limited.

Ibarra, H. (2005). Identity transitions, liminality and the dynamics of career change. INSEAD Working Paper 2005/24/OB.

Kahn, W. A. (1990). Psychological conditions of personal engagement and disengagement at work. Academy of Management Journal, 33, 692-724.

Kipnis, D. (1972). Does power corrupt? Journal of Personality and Social Psychology, 24 (1), $33-41$.

Landis, R. S., Beal, D. J., \& Tesluk, P. E. (2000). A comparison of approaches to forming composite measures in structural equation models. Organizational Research Methods, 3, 186-207.

Leavitt, K., \& Sluss, D. M. (2015). Lying for who we are: An identity-based model of workplace dishonesty. Academy of Management Review, 40(4), 587-610.

Lee, F. (1997). When the going gets tough, do the tough ask for help? Help seeking and power motivation in organizations. Organizational Behavior and Human Decision Processes, 72 (3), 336-363.

Lee, F. (2002). The social costs of seeking help. The Journal of Applied Behavioral Science, 38 (1), 17-35.

Leonard-Barton, D. (1989). Implementing new productions technologies: Exercises in corporate learning. In M. Von Glinow, \& S. Mohrmans (Eds.), Managing complexity in high 
technology industries: Systems and people (pp. 160-187). New York: Oxford University Press.

Lind, A. E., \& Tyler, T. R. (1988). The social psychology of procedural justice. New York, NY: Springer Science \& Business Media.

Lind, A. E., \& Tyler, T. R. (1992). A relational model of authority in groups. Advances in Experimental Social Psychology, 25, 115-192.

Little, T. D., Cunningham, W. A., Shahar, G., \& Widaman, K. F. (2002). To parcel or not to parcel: Exploring the question and weighing the merits. Structural Equation Modeling, 9, 151-173.

Maslowsky, J., Jager, J., \& Hemken., D. E. (2015). Estimating and interpreting latent variable interactions: A tutorial for applying the latent moderated structural equations method. International. Journal of Behavioral Development, 39, 87-96.

Meara, N. M. (2001). Just and virtuous leaders and organizations. Journal of Vocational Behavior, 58(2), 227-234.

Morrison, E. W. (1993). Newcomer Information Seeking: Exploring types, modes, sources, and outcomes. Academy of Management Journal, 36 (3), 557-589.

Mueller, J. S., \& Kamdar, D. (2011). Why seeking help from teammates is a blessing and a curse: A theory of help seeking and individual creativity in team contexts. Journal of Applied Psychology, 96(2), 263-276.

Muthén, L. K., \& Muthén, B. O. (2015). 1998-2015 Mplus User’s Guide. Version 7. Los Angeles, CA: Muthén \& Muthén

Muthén, B. O. (2012). Latent variable interactions. Retrieved from http://www.statmodel.com/download/LV\%20interaction.pdf

Nadler, A., Ellis, S., \& Bar, I. (2003). To seek or not to seek: The relationship between help seeking and job performance evaluations as moderated by task-relevant expertise. Journal of Applied Social Psychology, 33 (1), 91-109.

Newark, D. A., Bohns, V. K., \& Flynn, F. J. (2017). A helping hand is hard at work: Helpseekers' underestimation of helpers' effort. Organizational Behavior and Human Decision Processes, 139, 18-29.

Newman, R. S. (1998). Students' help seeking during problem solving: Influences of personal and contextual achievement goals. Journal of Educational Psychology, 90, 644-658. 
Newman, R. S. (2006). Implications and future research: Where do we go from here? In S. A. Karabenick \& R. S. Newman (Eds.), Help seeking in academic settings: Goals, groups, and context (pp. 297-308). Mahwah: Lawrence Erlbaum Associates.

Perlow, L. A. (1999). The time famine: Toward a sociology of work time. Administrative Science Quarterly, 44 (1), 57-81.

Podsakoff, P. M., MacKenzie, S. B., Paine, J. B. \& Bachrach. D. G. (2000). Organizational citizenship behaviors: A critical review of the theoretical and empirical literature and suggestions for future research. Journal of Management, 26, 513-563.

Podsakoff, P. M., MacKenzie, S. B., \& Podsakoff, N. P. (2012). Sources of method bias in social science research and recommendations on how to control it. Annual Review of Psychology, 65, 539-569.

Ragins, B.R., \& Dutton, J.E. (2007). Positive relationships at work: An introduction and invitation. In J.E. Dutton \& B. R. Ragins (Eds.), Exploring positive relationships at work: Building a theoretical and research foundation (pp. 3-25). Mahwah, NJ: Lawrence Erlbaum Associates.

Renn, R. W., \& Fedor, D. B. (2001). Development and field test of a feedback seeking, selfefficacy, and goal setting model of work performance. Journal of Management, 27 (5), 563-583.

Roberts, L. M. (2007). From proving to becoming: How positive relationships create a context for self-discovery and self-actualization. In J. Dutton \& B. Ragins (Eds.), Exploring positive relationships at work (pp. 29-45). Mahwah, NJ: Erlbaum

Rogers, C. R. (1957). The necessary and sufficient conditions of therapeutic personality change. Journal of consulting Psychology, 21 (2), 95-103.

Rogers, K. M., \& Ashforth, B. E. (2015). Respect in organizations: Feeling valued as "we" and “me.” Journal of Management. doi: 10.1177/0149206314557159

Rousseau, D. M., \& Ling, K. (2007). Commentary: Following the resources in positive organizational relationships. In Jane E. Dutton and Belle R. Ragins (Eds.) Exploring positive relationships at work: Building a theoretical and research foundation (pp. 373384). Mahwah, NJ: Lawrence Erlbaum. 
See, K. E, Morrison, E. W., Rothman, N. B., \& Soll, J. B. (2011). The detrimental effects of power on confidence, advice taking, and accuracy. Organizational Behavior and Human Decision Processes, 116 (2), 272-285.

Shamir, B., House, R. J., \& Arthur, M. B. (1993). The motivational effects of charismatic leadership: A self-concept based theory. Organization Science, 4, 577-594.

Sluss, D. M., \& Ashforth, B. E. (2007). Relational identity and identification: Defining ourselves through work relationships. Academy of Management Review, 32(1), 9-32.

Smith, H. J., Tyler, T. R., Huo, Y. J., Ortiz, D. J., \& Lind. A. E. (1998). Group membership, selfesteem, and procedural justice. Journal of Experimental Social Psychology, 34: 470-493

Smith, J. H., Tyler, T. R., \& Huo, Y. J. (2003). Interpersonal treatment, social identity and organizational behavior. In Alexander S. Haslam, Dan van Knippenberg, Michael Platow and Naomi Ellemers (Eds.), Social identity at work: Developing theory for organizational practice (pp. 155-171). Philadelphia, PA: Psychology Press.

Spector, P. E. (1994). Using self-report questionnaires in OB research: A comment on the use of a controversial method. Journal of Organizational Behavior, 15, 385-392.

Steele, C. M. (1988). The psychology of self-affirmation: Sustaining the integrity of the self. Advances in Experimental Social Psychology 21: 261-302

Stephens, J.P., \& Carmeli, A. (2017). Relational Leadership and Creativity: The Effects of Respectful Engagement and Caring on Meaningfulness and Creative Work Involvement. In S. Hemlin \& M. D. Mumford (Eds.), Handbook of Research on Creativity and Leadership. Edward Elgar Publishing

Taber, T. D., \& Deosthali, K. (2014). Analysis of self-reported motives for task-related helping: Implications for an integrated theory of helping. Journal of Business Psychology, 29, 343-366.

Tyler, T. R., \& Blader, S. L. (2000). Cooperation in groups: Procedural justice, social identity and behavioral engagement. Philadelphia, U.S.A.: Psychology Press.

Tyler, T. R., \& Lind. A. E. (1992). A relational model of authority in groups. Advances in Experimental Social Psychology, 25, 115-191.

Tyler, T. R., \& Smith. J. H. (1999). Justice, social identity, and group processes. In Tom R. Tyler, Roderick M. Kramer and Oliver P. John (Eds.), The psychology of the social self (pp. 223-264). Hillsdale, NJ: Lawrence Erlbaum Associates. 
van Kleef, G. A., Oveis, C., van der Lowe, I., LuoKogan, A., Goetz, J. L., \& Keltner, D. (2008). Power, distress, and compassion: Turning a blind eye to the suffering of others. Psychological Science, 19 (12), 1315-1322.

van der Rijt, J., Van den Bossche, P., van de Wiel, M. W., De Maeyer, S., Gijselaers, W. H., \& Segers, M. S. (2013). Asking for help: A relational perspective on help seeking in the workplace. Vocations and Learning, 6 (2), 259-279.

van Ginkel, W. P., \& van Knippenberg, D. (2008). Group information elaboration and group decision making: The role of shared task representations. Organizational Behavior and Human Decision Processes, 105, 82-97.

VandeWalle, D., Ganesan, S., Challagalla, G. N., \& Brown, S. P. (2000). An integrated model of feedback-seeking behavior: disposition, context, and cognition. Journal of Applied Psychology, 85 (6), 996-1003.

Vinarski-Peretz, H., Binyamin, G., \& Carmeli, A. (2011). Subjective relational experiences and employee innovative behaviors in the workplace. Journal of Vocational Behavior, 78(2), 290-304.

Vogus, T. J., \& Iacobucci, D. (2016). Creating highly reliable health care: How reliabilityenhancing work practices affect patient safety in hospitals. ILR Review, 69(4), 911-938.

Whitaker, B. G., \& Levy, P. E. (2012). Linking feedback quality and goal orientation to feedback seeking and job performance. Human Performance, 25 (2), 159-178.

Wrzesniewski, A., Dutton, J. E., \& Debebe, G. (2003). Interpersonal sensemaking and the meaning of work. Research in Organizational Behavior, 25, 93-135. 
Table 1. Means, Standard Deviations, Correlations among of Study Variables

$\begin{array}{lllllll}\text { Mean } & \text { SD } & 1 & 2 & 3 & 4 & 5\end{array}$

\begin{tabular}{|c|c|c|c|c|c|c|c|}
\hline $\begin{array}{l}\text { 1. Tenure in the } \\
\text { organization }\end{array}$ & 6.21 & 5.87 & & & & & \\
\hline 2. Trust & 4.17 & .50 & .00 & & & & \\
\hline $\begin{array}{l}\text { 3. Respectful } \\
\text { engagement with } \\
\text { one's supervisor } \\
\text { (RE) }\end{array}$ & 4.26 & .69 & $.30^{* * *}$ & $.21^{* * *}$ & & & \\
\hline $\begin{array}{l}\text { 4. Psychological } \\
\text { safety (PS) }\end{array}$ & 3.70 & .71 & $.23^{* * *}$ & $.37^{* * *}$ & $.41^{* * *}$ & & \\
\hline 5. Help-Seeking (HS) & 4.19 & .66 & $-.14^{* *}$ & $.19^{* *}$ & $.30^{* * *}$ & $.18^{* *}$ & \\
\hline $\begin{array}{l}\text { 6. Job performance } \\
\text { (supervisory-rating; } \\
\text { JPS) }\end{array}$ & 4.10 & .58 & -.06 & -.04 & $.17^{* *}$ & .04 & $.30^{* * *}$ \\
\hline
\end{tabular}


Table 2

Model Paths

\begin{tabular}{|c|c|c|c|c|c|c|}
\hline & Path & Path Description & $\begin{array}{c}\text { Psychological } \\
\text { Safety }\end{array}$ & Estimate & Significance & $95 \% \mathrm{CI}$ \\
\hline \multirow{2}{*}{$\begin{array}{l}\text { Direct Effect } \\
\text { Simple Slope }\end{array}$} & \multirow[t]{2}{*}{ Path 1} & \multirow[t]{2}{*}{$\mathrm{RE} \rightarrow \mathrm{HS}$} & Low & .570 & \multirow[t]{2}{*}{$* * *$} & \\
\hline & & & High & -.172 & & \\
\hline \multirow[t]{2}{*}{ Indirect Effect } & \multirow[t]{2}{*}{ Path 2} & \multirow[t]{2}{*}{$\mathrm{RE} \rightarrow \mathrm{HS} \rightarrow \mathrm{JPS}$} & Low & .211 & \multirow[t]{2}{*}{$* *$} & $(0.095,0.413)$ \\
\hline & & & High & -.064 & & $(-0.263,0.053)$ \\
\hline \multirow[t]{2}{*}{ Direct Effect } & \multirow[t]{2}{*}{ Path 3} & \multirow[t]{2}{*}{$\mathrm{RE} \rightarrow \mathrm{JPS}$} & Low & .143 & & \\
\hline & & & High & .146 & & \\
\hline
\end{tabular}

${ }^{* * p} p<0.01, * * * p<0.001$ 
Figure 1. Graphical Illustration of the Findings of the Hypothesized Model

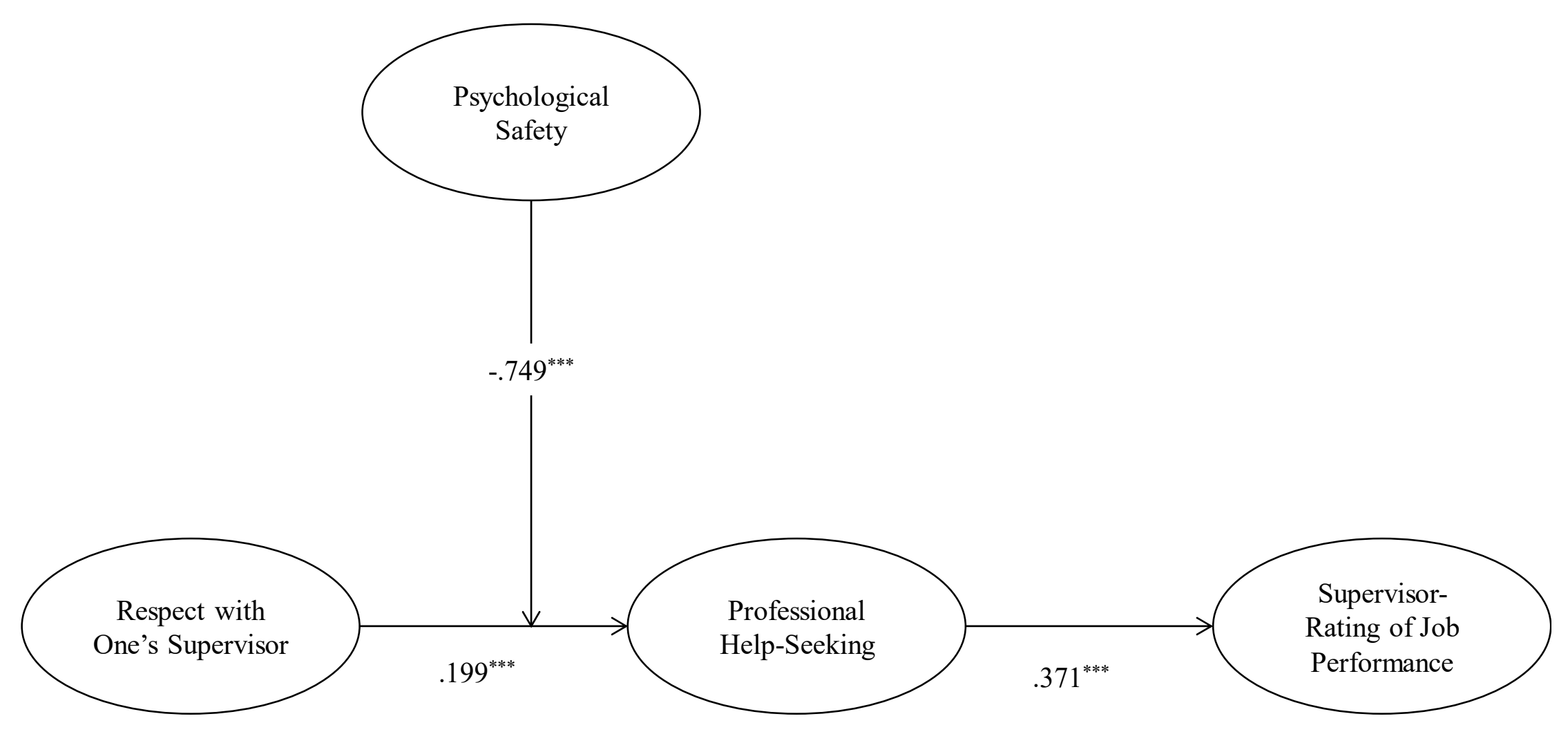

Note. For clarity, only the main variables are shown.

$* * * p<0.001$ 
Figure 2. The Interactive Effect of Respectful Engagement with One's Supervisor and Psychological Safety on Help-Seeking Behaviors

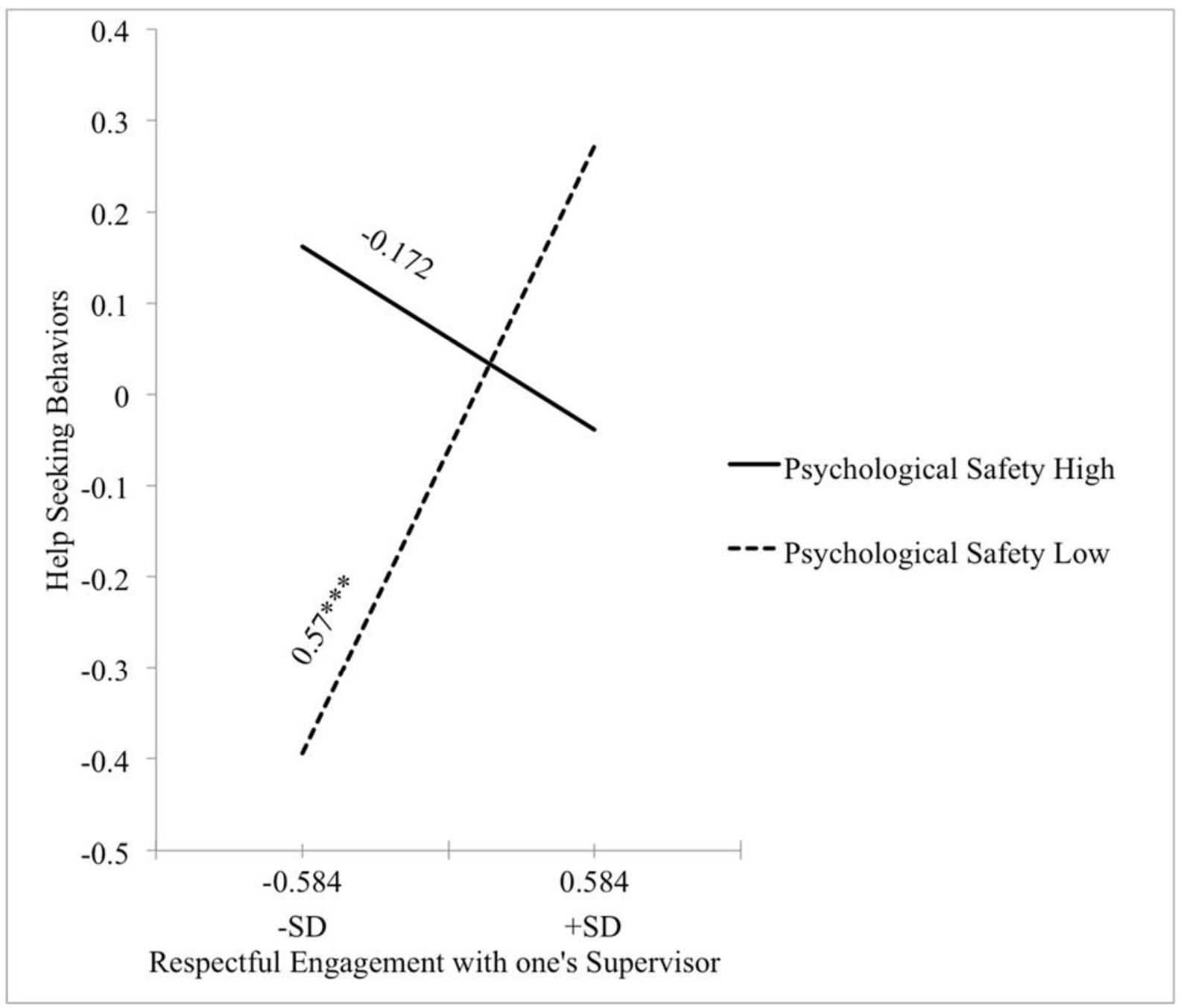




\begin{tabular}{|c|c|c|c|c|c|}
\hline \multicolumn{6}{|c|}{ Appendix A. Confirmatory Factor Analysis - Fit Statistics } \\
\hline & \multirow{4}{*}{$\begin{array}{c}\text { 4-Factor Model } \\
\text { (without PS) }\end{array}$} & \multirow{4}{*}{$\begin{array}{c}\text { 3-Factor Model } \\
\text { (without PS) }\end{array}$} & 1-Factor & \multirow[t]{4}{*}{ 5-Factor Model } & \multirow[t]{4}{*}{ 4-Factor Model } \\
\hline & & & Model & & \\
\hline & & & & & \\
\hline & & & & & \\
\hline$\chi^{2}$ & 132.29 & 292.865 & 981.76 & 254.837 & 340.237 \\
\hline df & 48 & 51 & 54 & 80 & 84 \\
\hline \multirow[t]{2}{*}{ RMSEA } & 0.84 & 0.138 & 0.263 & 0.094 & 0.111 \\
\hline & $(0.067,0.101)$ & $(0.123,0.154)$ & $(0.249,0.278)$ & $(0.081,0.107)$ & $(0.099,0.123)$ \\
\hline SRMSR & 0.059 & 0.101 & 0.179 & 0.067 & 0.090 \\
\hline $\mathrm{AIC}$ & 4935.661 & 5090.236 & 5773.138 & 6767.529 & 6844.929 \\
\hline CFI & 0.942 & 0.834 & 0.365 & 0.898 & 0.851 \\
\hline H0 & -2425.83 & -2506.118 & -2850.569 & -3328.764 & -3371.464 \\
\hline Highest Correlation & $\mathrm{HS}<->$ JPS & & & $\mathrm{PS}<->\mathrm{RE}$ & \\
\hline coefficients & 0.42 & & & 0.52 & \\
\hline
\end{tabular}

RE = Respectful engagement; JPS = Job performance; PS = Psychological safety; Trst = Trust

A 4-factor model analysis was compared to a 3-factor model (where HS and JPS were loaded by the same latent variable), and 1factor model (where all items were loaded by the same latent variable). A 5-factor model analysis was compared with a 4-factor model (where PS and RE were loaded by the same latent variable). 


\begin{tabular}{|c|c|c|c|}
\hline \multicolumn{4}{|c|}{ Appendix B. LMS Approach - Fit Statistics } \\
\hline & & Model 1 & Model 2 \\
\hline Free Parameters $^{\#}$ & & 57 & 59 \\
\hline \multirow[t]{2}{*}{ RMSEA } & & 0.107 & \\
\hline & & $(0.095,0.118)$ & \\
\hline SRMSR & & 0.088 & \\
\hline AIC & & 6759.748 & 6745.005 \\
\hline CFI & & 0.856 & \\
\hline H0 & & 3322.874 & -3313.502 \\
\hline \multicolumn{4}{|c|}{$\begin{array}{l}\text { RE = Respectful engagement; PS = Psychological safety; } \\
\text { Note. The LMS approach was employed to test to models: 1) A model in which the moderator PS was included but not interacted } \\
\text { with RE, and 2) A model with the moderator interacted. } \\
\text { \# The difference of the number of free parameters is due to the interaction between PS and RE which was included in the model, } \\
\text { both for JPS and HS. The latter is not shown in the plot, since it is not significant }\end{array}$} \\
\hline \multicolumn{4}{|c|}{ Appendix C. Model Results } \\
\hline \multirow[t]{2}{*}{ Controls: } & Tenure & $-0.021 * *$ & -0.009 \\
\hline & Trust & $0.212 *$ & $-0.247 *$ \\
\hline \multirow[t]{2}{*}{ Main effects } & $\mathrm{RE}$ & $0.199 *$ & 0.145 \\
\hline & PS & 0.124 & 0.084 \\
\hline Interaction: & PS X RE & $-0.749 * * *$ & 0.002 \\
\hline Mediator: & HS & & $0.371 * * *$ \\
\hline
\end{tabular}

$\mathrm{RE}=$ Respectful engagement; PS = Psychological safety; HS = Help-seeking; JPS = Job performance 